\title{
Feasibility of Applying Mobile Micro-learning to College English Learning
}

\author{
Jiaying Meng \\ Teaching and Research Institute of Foreign Languages \\ Bohai University \\ Jinzhou, China \\ mengjiaying1@163.com
}

\author{
Zhimin Li \\ Harbin Flying Academy \\ Harbin, China \\ wzf402@163.com
}

\begin{abstract}
To prove the feasibility of applying mobile microlearning to college English learning, this thesis adopts the methods of investigation and data collecting and the FRAME analytical model. The questionnaires are designed to investigate learners' learning conditions from four aspects, namely, technical support of mobile devices, learning resources of mobile microlearning, learners' initiatives and technical and emotional support given to learners. The results of the questionnaires prove that with the features of convenience, flexibility and interactivity, it is feasible to adopt mobile micro-learning method in college English teaching and learning.
\end{abstract}

Keywords-mobile learning, micro-learning, FRAME model, college English learning

\section{INTRODUCTION}

In recent years, with the development of network technology and mobile communication technology, in the field of digital learning there appear new ways of learning such as mobile learning and ubiquitous learning. An increasing number of learners tend to adopt mobile micro-learning with smart mobile phone, tablet computer and other mobile devices. According to the requirement for college English curriculum, teachers should make full use of multimedia and network technology, replace traditional teacher-centered teaching mode with new methods focusing on the improvement of students' comprehensive abilities of English and apply multimedia and modern educational technologies to realize the reform of college English teaching. This thesis firstly introduces basic theories about mobile learning and micro- learning; secondly it applies Koole's Framework for the Rational Analysis of Mobile Education Model (FRAME) to assess the effectiveness of mobile micro-learning on the basis of questionnaires and investigation; finally it draws the conclusion that to adopt mobile micro-learning method in college English learning is feasible and effective basing on the concrete data from research and investigation of the present situation of mobile microlearning of English in the experimental class.

\section{BASIC THEORIES ABOUt MobILE LEARNING AND MiCRO- LEARNING}

With the rapid development of information technology, digital technology and the mobile communications technology, a variety of intelligent mobile terminals, such as smart phones and tablet PCs, become more popular than before. Being portable, convenient and of small size, these mobile devices have become an indispensable part of people's life. Except for the purpose of entertainment and communication, these mobile devices can also be used to conduct studies with small learning units, which is mobile micro-learning. The definition of mobile micro-learning can be understood from the following aspects.

\section{A. Definition of Mobile Learning}

The concept of mobile learning was first introduced into China by the international distance educator Desmond Keegan in 2000. After more than ten years of development, mobile learning has become a hot research topic in the field of digital teaching. At present, there is no uniform definition of mobile learning in the academic community. Generally speaking, we can understand it from four different perspectives. Firstly, it can be considered as a form of distance learning; secondly, it can be considered as extension of e-learning because it has the same learning content with e-learning; thirdly, from cognitive perspective, with the nature of mobility and situationdependence, it can be viewed as a totally new form of learning; fourthly, from the perspective of technology, mobile learning can be regarded as the application of mobile computing in the educational field.[1]Though with different researching perspectives, mobile learning can be generalized as a learning form through which learners can receive learning resources with wireless communication network and mobile devices. The features of high flexibility, abundant interactivity and situated learning dramatically meet learners' needs for flexible and personalized learning.

\section{B. Definition of Micro-learning}

In 2004, Austria study expert Lindner first proposed the theory of micro-learning. After ten years of research, the development of this theory has made great progress. Researchers both home and abroad explained the concept of micro-learning from different perspectives. From the perspective of media characteristics, Lindner pointed that micro-learning is a new form of learning based on microcontent and micro-media; [2] Theo Hug defined micro-learning as learning activities based on small learning unit in relatively short learning time; [3]Bruck regarded micro-learning as a way of learning which focuses on small, loose yet closely related learning units in digital environment; [4]Professor Zhu Zhiting stressed the new learning experience micro-learning has given to learners.[5]With this learning form, learners' learning 
activities are not confined by time and place; they can study anytime, anywhere with relatively small learning units for a short time. As a new form of learning, micro-learning has the characteristics of convenience and flexibility and are welcomed by more learners.

\section{Relationship between Mobile micro-learning and English Learning}

Although mobile learning and micro-learning both rely on mobile communication technology, wireless network technology and mobile devices to support the learning process, they have different focus. Mobile learning stresses the flexibility of time and space in the learning process, while micro-learning emphasizes the shortness of time and the fragmentation of learning content. Mobile micro-learning makes full use of the advantages of both mobile learning and micro-learning, that is, to receive micro-content with mobile terminals to study anytime anywhere. Therefore, it is quite convenient to update and supplement learners' existing knowledge system with modular knowledge fragments.

English learning has its distinctive features. Firstly, English learning consists of many different aspects. Horizontally, it covers listening, speaking, reading, writing and translating; vertically, it includes vocabulary, sentence, and discourse and so on; secondly, language learning has the characteristic of relevance with each part closely related; thirdly, language learning stresses the construction of language situations. The input and output of language is very critical to learners; fourthly, the learning of knowledge points can be separated and learners can learn according to the degree of difficulties or their own needs.

To adopt the method of mobile micro-learning to learning English, learners can divide it into different and related microcontent and learn with mobile devices. In this way not only can learners make good use of their fragmented time to learn English but they also can communicate effectively with both their peers and teachers. In the meanwhile, learners can contact correct input through some mobile learning platforms which can satisfy learners' need for language learning environment.

\section{Model ANALYSIS OF MOBILE MiCRO-LEARNING}

The Framework for the Rational Analysis of Mobile Education (FRAME) was proposed by Marguerite Koole of University of Saskatchewan. It has drawn great attention from researchers of mobile learning at home and abroad. This analytical model describes the intersection of mobile learning as a process involving mobile technology, human learning capabilities, and social interaction [6]. In the FRAME analysis model, Koole regarded mobile learning as learners' learning experience in a particular information environment. Learners use or create information through mobile technologies either in a group or as an individual. It is this process of interaction that makes information meaningful and facilitates learning activates. The FRAME model of Koole shows the relationship between the three different levels and the intersection of the mobile learning through the Venn diagram, as is shown in Fig. 1. [7]

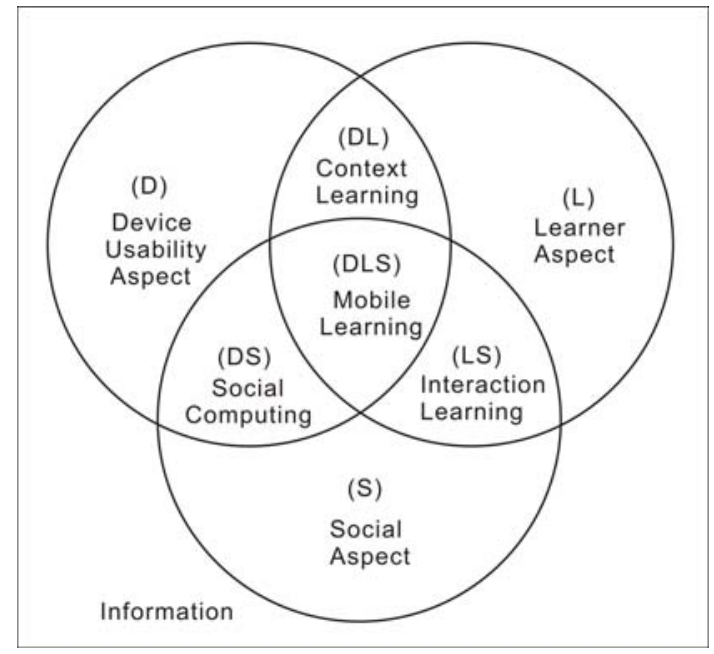

Fig. 1. Koole's FRAME Model

In the picture, the three circles represent the device usability (D), learner (L) and social aspects(S).The region where two circles overlap, the secondary intersections, contain attributes that belong to both aspects. The attributes located inside the secondary intersections of context learning (DL) and social computing (DS) describe the affordances of mobile devices. The secondary intersection labeled interaction learning (LS) contains instructional and learning theories viewed through the philosophical lens of social constructivism. All three aspects overlap at the primary intersection (DLS) which is located in the center of the Venn diagram.

This research in the thesis explores the feasibility of mobile micro-learning in college English learning based on the FRAME analytical model. The subjects of the research are 120 students in the author's class. The research is conducted in the way of questionnaires. The research employs the FRAME analytical model to analyze the feasibility of mobile microlearning in college English studies and generalizes four analytical perspectives, namely, technical support of mobile devices, learning resources of mobile micro-learning, learners' initiatives and technical and emotional support given to learners. The questionnaires are designed according to these four aspects and given to 120 students and all these questionnaires returned validly.

\section{RESUlts AND ANALYSIS OF THE RESEARCH}

\section{A. Technical Support for Mobile Devices}

Since mobile micro-learning is a new form of learning based on information technology, the support of technology environment is an important guarantee for its realization. The research first investigates the conditions of hardware configuration of students' mobile devices. 


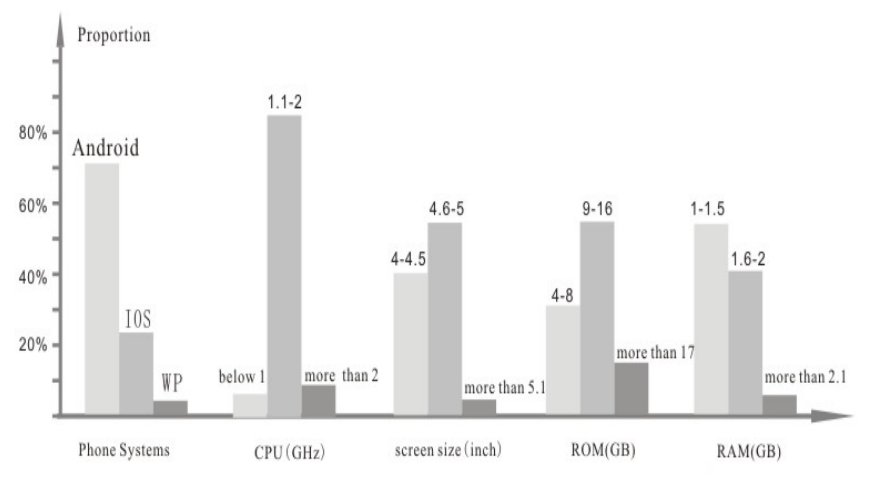

Fig. 2. Hardware configuration form

As is shown in Fig.2, current mobile devices used by students are mainly smart phones. In recent years, with the rapid development of digital technology, the function of mobile phones had changed from making phone calls and receiving messages to a multifunctional combination of telecommunication, Internet surfing and multimedia. From the perspective of hardware development, the frequency of CUP has developed from several hundred $\mathrm{Hz}$ to1-3GHz;single core processor has been gradually eliminated or applied to the lowend mobile phones; the mainstream of mobile phones have achieved dual core, quad core or eight core to move. Strong processor performance can ensure the smooth operation of the mobile learning software and the occupation of the lower power consumption. Random access memory (RAM) is responsible for the operation of the mobile phone software, storage of exchanging data after software operation. Presently, the RAM of mainstream smart phones has reached $2 \mathrm{~GB}$ to 3GB.The screen of mobile phone is also an important element in the process of mobile learning. The size of mobile phone has reached more than four inches and great progress has been made in the color, brightness, contrast and other aspects of phone. The large windows and excellent color reproduction capabilities bring good experience to learners. Read-only memory (ROM), graphics processor (GPU) and other hardware also developed rapidly, building a strong mobile phone hardware environment together. Relying on a strong hardware environment of smart phones, the smart phone operating system has very rich functions. At present, the commonly used operating systems include Android, iOS, Windows and Phone, with each operating system provides a wealth of third party software installation.

According to the result of the survey, smart phones have been very popular in college students and has provided necessary material basis for mobile micro-learning.

\section{B. Learning Resources of Mobile Micro-learning}

The choice of resources for mobile micro-learning has to take both the technical features of smart phones and the needs of learners into account. To investigate the application of learning resources in mobile micro-learning process, the research divides the resources into four types, namely, vocabulary application, dictionary application, oral practice application, and textbook application.
The result of the survey indicates that the dictionary application is downloaded the most, reaching nearly about $85 \%$; the proportion of vocabulary application downloaded is about 50\%; oral English and textbook applications are least downloaded.

The survey results show that students use mobile phones and other mobile devices to conduct mobile micro-learning mainly to solve concrete problems met in learning or to prepare for English tests. There still lack a sound system to use these learning resources to improve comprehensive abilities of English.

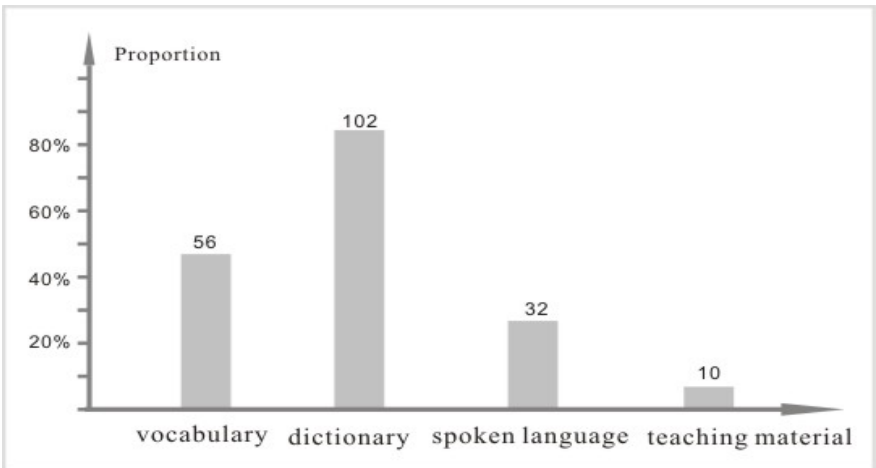

Fig. 3. Learning resources download form

\section{Learners' Learning Initiatives}

Learners are the main body in the FRAME analytical model. Mobile devices provides a basis for mobile micro-learning, however, the learning effect depends on learners' initiatives. According to the result of the survey, nearly $70 \%$ of the students can keep mobile micro-learning with a high frequency; $26 \%$ of the students are of poor initiative, but they still can use smart phone to solve problems the met in studies; few student don't use mobile phones to study. Most students can use their mobile devices to help learn English.

\section{Technical and Emotional Support in Mobile Micro- learning}

In the FRAME model, to ensure learners' learning effect, there has to be intersection between learners and social aspect, in other words, the communication and support from teachers and their peers.

The results show that when they encounter problems, $57 \%$ of the students chose to directly find solutions using the Internet, $32 \%$ of the students chose to communicate with the students, and $9 \%$ of the students asked their teacher, $2 \%$ of the students chose to ignore the problem. According to the results, students are more willingly to turn to the Internet or their peers when they have problems in learning. Teachers have to do more to provide technical and emotional support for students and try to play a greater role in facilitating students to carry out mobile micro-learning.

\section{CONCLUSION}

Mobile learning is a learning method with which learners can receive learning resources with wireless communication 
network and mobile devices; micro-learning, also known as the fragmented learning, is different from traditional systematic learning method. With this learning form, learners' learning activities are not confined by time and place; they can study anytime, anywhere with relatively small learning units for a short time. Combing the two learning forms, mobile microlearning has the features of convenience, flexibility and interactivity. To adopt the method of mobile micro-learning to English learning, learners can divide the knowledge into different and related micro-content and learn with mobile devices. In this way not only can learners make good use of their fragmented time to learn English but they can also communicate effectively with both their peers and teachers. In the meanwhile, learners can contact correct input through some mobile learning platforms which can satisfy learners' need for language learning environment. This research in the thesis adapts the FRAME analytical model to analyze the feasibility of mobile micro-learning in college English studies from four perspectives, namely, technical support of mobile devices, learning resources of mobile micro-learning, learners' initiatives and technical and emotional support given to learners. The result data of the research proves that it is feasible to adopt mobile micro-learning method in college English learning.

\section{REFERENCES}

[1] Zhang Hongling, Zhuye, Sun Guifang, et al. Web-Based Foreign Language Teaching: Theories and Designing [M]. Shanghai: Shanghai Foreign Language Education Press, 2000, p.67-80.(In Chinese)

[2] Lindner M, Peter A. Bruck. Micromedia and Corporate Learning: Proceedings of the 3rd International Microlearning 2007 Conference [M] Innsbruck: Innsbruck University Press, 2007,p.52-55

[3] Hug T. Microlearning: A New Pedagogical Challenge (Introductory Note)[C]. 2005.

[4] Bruck P.A, Motiwalla L B, Foerster F A. Mobile learning with microcontent: A framework and evaluation[J]. 2012.Zhu Zhiting. Report on the Foresightful Research of Educational Technology[J].E-education Research, (2012)No.4,p.5-14.

[5] Zhu Zhiting. Report on the Foresightful Research of Educational Technology[J].E-education Research, (2012)No.4,p.5-14.(In Chinese)

[6] Ally M, Ally M. Mobile Learning: Transforming the Delivery of Education and Training [M]. 2009.

[7] Koole M, Ally M. Framework for the Rational Analysis of Mobile Education (FRAME) Model: Revising the ABCs of Educational Practices[C].International Conference on Networking, International Conference on Systems and International Conference on Mobile Communications and Learning Technologies, 2006. Icn/icons/mcl. IEEE, 2006:59-65. 